\title{
Phosphorylated Akt1 expression is associated with poor prognosis in cutaneous, oral and sinonasal melanomas
}

\author{
Ciro Soares ${ }^{1}$, Thayná Melo de Lima Morais ${ }^{1}$, Roman Carlos ${ }^{2}$, Fernanda Viviane \\ Mariano $^{1,3}$, Albina Altemani ${ }^{1,3}$, Maria Goretti Freire de Carvalho ${ }^{4}$, Marcelo Brum \\ Corrêa ${ }^{5}$, Rodrigo Ribas Dias dos Reis ${ }^{6}$, Luciana Schultz Amorim7, Oslei Paes de \\ Almeida $^{1}$ and Jacks Jorge ${ }^{1}$

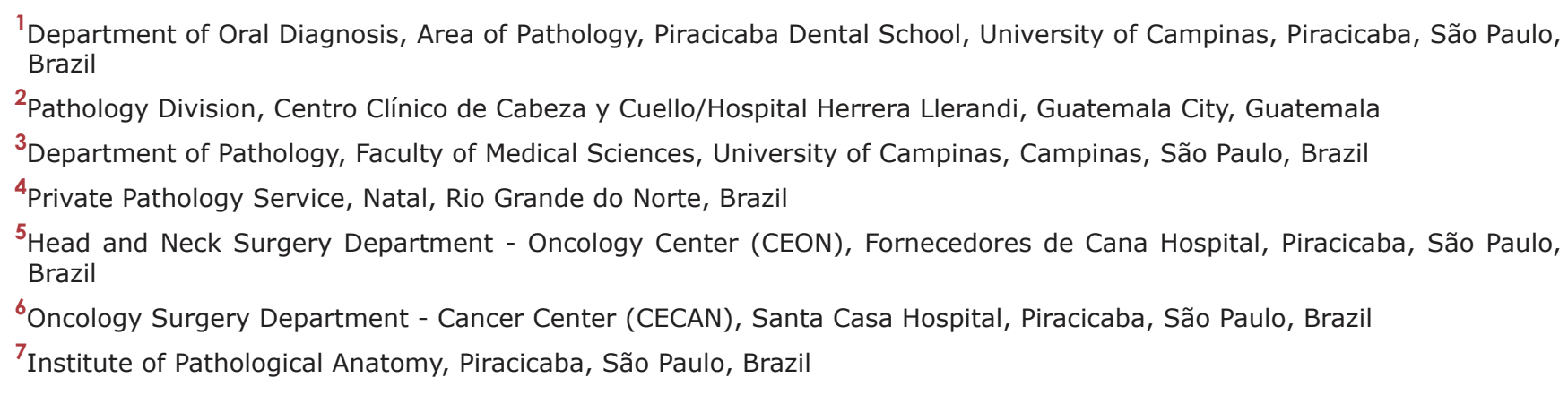

Correspondence to: Ciro Soares, email: ciro.dss@gmail.com

Keywords: cutaneous melanomas; mucosal melanomas; $\mathrm{p}-A k+1$; immunohistochemistry; prognosis

Received: August 08, $2018 \quad$ Accepted: November 26, $2018 \quad$ Published: December 18, 2018

Copyright: Soares et al. This is an open-access article distributed under the terms of the Creative Commons Attribution License 3.0 (CC BY 3.0), which permits unrestricted use, distribution, and reproduction in any medium, provided the original author and source are credited.

\section{ABSTRACT}

Melanomas are highly aggressive tumours derived from melanocytes, which occur most commonly in the skin. Occasionally, these tumours may appear in oral and sinonasal mucous membranes. In this study, we performed a comparative analysis of the Phosphorylated Akt1 ( $p$-Akt1) expression in 144 patients affected by cutaneous (CM), 34 oral cavity (OM), and 31 sinonasal melanomas (SNM). Similar to the metastatic cutaneous melanomas, p-Akt1 was overexpressed in 17/34 of the oral cavity and 20/31 of the sinonasal melanomas. In addition, the p-Akt1-nuclear expression was associated with poorer cancer-specific survival in cutaneous $(P<.0001)$, oral $(P<.0001)$, and sinonasal $(P=.001)$ melanomas. Multivariate analysis showed $p$-Akt1 to be an independent prognostic marker in oral $(P=.041)$ and sinonasal $(P<.0001)$ melanomas patients. In conclusion, p-Akt1 overexpression is an independent prognostic marker in mucosal melanomas and is significantly up-regulated in sinonasal melanomas. As both mucosal and metastatic cutaneous melanomas showed high frequency of p-Akt1 expression, these findings suggest that mucosal melanomas have a biological behaviour, similar to the aggressive cutaneous melanomas.

\section{INTRODUCTION}

Cutaneous melanomas represent about $1.6 \%$ of all cancers, and discreet advances in their treatment have been made over the last decades. Nevertheless, this tumour still remains deathly, especially the metastatic disease [1]. It is estimated that melanomas with lymph nodal metastases are responsible for 59,782 global deaths, with mean overall survival rate of $13 \%$ in 5 years [2]. Controlling the advanced-stage disease is the major problem for the treatment of melanomas. Thus, for the development of targeted therapies, making progress in understanding the molecular factors that influence the aggressiveness of the metastatic melanomas is essential. 
Until now, comparative studies with melanomas from different anatomic sites that assessed the potential differences and similarities between these tumours are scarce [3-6]. Overall, the etiologic factors and the clinical and biological behaviour of cutaneous melanomas are very distinct from the other melanomas [7, 8]. For example, mucosal melanomas constitute a particular subset of all melanomas characterized by high-aggressive behaviour, tendency to metastasize and consequently association with marked worse prognosis. Sinonasal melanomas in some series have presented a highmortality index (near 100\%) [8, 9]. Clinicopathological parameters determine the prognosis and staging of the melanomas from different anatomic sites [10].

The use of biological markers, especially by immunohistochemistry, for predict prognosis is still poorly explored in mucosal melanomas. The serine/threonine protein B Kinase, known as Akt, has an oncogenic function in several tissues by regulating cell proliferation, migration and invasion [11]. The overexpression of p-Akt1 is correlated with adverse outcome in breast [12], gastric [13] and oesophageal squamous cell carcinomas [14]. In the context of melanoma, an overgrowing interest in determining as p-Akt1 acts during melanoma progression $[15,16]$ has been recently observed, and its inhibition has emerged as an interesting targeted therapy for these tumours [17].

Although some studies have demonstrated the role of p-Akt1 in several cancers, including melanoma metastases in a mice model [18], no studies have evaluated the prognostic value of the immunohistochemical expression of p-Akt1 in different subsets of melanomas. In the present study, we evaluated the immunohistochemical expression and the prognostic value of p-Akt1 expression in a large cohort of cutaneous, oral, and sinonasal melanomas.

\section{RESULTS}

\section{Cutaneous melanomas}

The age range of the cohort of 144 patients affected by cutaneous melanomas was from 20 to 88 years old at diagnosis (mean age, 56). The three most common sites were the trunk $(64 / 144)$, followed by the lower limbs $(40 / 144)$ and the head and neck area (22/144) (Table 1). The median follow-up period was 62 months, ranging from 14 months to 18 years. The 3 - and 5-year cancerspecific survival (CSS) rates were $89.9 \%$ and $69.3 \%$, respectively. Detailed clinicopathological data from the cutaneous melanomas is shown in Supplementary Table 1.

Cancer-specific survival (CSS) rates for cutaneous melanomas based on clinicopathological parameters are shown in Table 1. Significant prognostic factors for CSS using a univariate model were Age $(P=.013)$, Ulceration $(P<.0001)$, Breslow's Thickness $(P<.0001)$, Mitotic rate $(P<.0001)$, Clark's level $(P=.002)$, Distant metastasis $(P<.0001)$, AJCC-stage $(P<.0001)$ and $\mathrm{p}$-Akt1 expression
$(P<.0001)$ Figure 1; while the unique independent prognostic factor in a multivariate analysis was Breslow Thickness $(\mathrm{HR}=10.855, P=.041)$.

\section{p-Akt1 is an independent prognostic marker in Oral melanomas}

For oral melanomas, 34 patients were enrolled in this study, with a mean age of 52 years, and regarding sex, 18 were men and 16 women. The main locations for oral melanomas were the hard palate $(15 / 34)$, the tooth alveoluls (5/34), and other areas (14/34). The OM clinicopathological data are listed in Supplementary Table 2. The median follow-up period was 23.5 months, ranging from 2 months to 14 years. The 3 - and 5-year CSS rates were $49.1 \%$ and $35.8 \%$, respectively.

Using the multivariate analysis, the mitotic rate $(P=.001)$, presence of vascular invasion $(P<.0001)$, neural invasion $(P=.011)$, epithelioid cellular morphology $(P=.001)$, and $\mathrm{p}-\mathrm{Akt1}$ nuclear expression were considered prognostic factors for CSS in oral melanomas $(P<0.001$, Log-rank $=28.086$; Figure 2). More interestingly, in the Cox regression model against established pathological prognostic factors such as mitotic rate, cellular morphology, vascular and neural invasion, p-Akt1 expression demonstrated to be an independent prognostic factor for oral melanomas Table $2(\mathrm{HR}=11.397, P=.041)$.

\section{p-Akt1 is an independent prognostic marker in sinonasal melanomas}

Regarding the sinonasal melanomas (SNM), out of 31 patients, 15 were women and 16 men of ages between 24 and 82 (mean age, 55). The tumours were located at nasal cavity $(41.9 \%)$, maxillary sinus $(38.7 \%)$, and rhinopharynx (19.4\%). Detailed clinicopathological data for SNM are shown in Supplementary Table 3. The median follow-up for SNM patients was 30 months, ranging from 3 months to 18.6 years, and the CSS 3-years and 5-years survival rates were $56.9 \%$ and $31.8 \%$, respectively.

In a univariate model, vascular invasion $(P=.042)$ and fusiform cellular morphology $(P=.001)$ were associated with poorer CSS for patients with SNM (Table 3). p-Akt1 was associated with poor CSS for SNM in the univariate $(P=.001, \log$-rank $=11.079)$ and multivariate (HR $=65.726, P<.0001)$ models Figure 3 . In addition, the clinical grade was also an independent prognostic marker for SNM $(\mathrm{HR}=7.351, P=.019$, Table 3$)$.

\section{p-Akt1 expression is associated with clinicopathological parameters in melanomas}

In the cutaneous melanomas patients, $\mathrm{p}$-Akt1 showed positive association with ulceration $(P<.0001)$, growth phase $(P<.0001)$, Breslow's Thickness $(P<.0001)$, mitotic rate $(P=.003)$, Clark's Level $(P<.0001)$, metastasis 
Table 1: The relationship between clinicopathological characteristics of patients with cutaneous melanomas, p-Akt1 expression and cancer-specific survival

\begin{tabular}{|c|c|c|c|c|c|c|}
\hline \multirow{2}{*}{ Factors } & \multirow{2}{*}{$\begin{array}{c}\text { Sample } \\
n(\%)\end{array}$} & \multicolumn{2}{|c|}{ CSS (\%) } & \multirow{2}{*}{$\begin{array}{c}\text { Univariate } \\
P \text { (log-rank) }\end{array}$} & \multicolumn{2}{|l|}{ Multivariate } \\
\hline & & 3-years & 5 -years & & HR (95\% CI) & $P$-value \\
\hline \multicolumn{7}{|l|}{ Age } \\
\hline$<56$ & 78 & $94.8 \%$ & $87.6 \%$ & $.013(6.118)$ & $2.029(.969-4.250)$ & .061 \\
\hline$\geq 56$ & 66 & $82.5 \%$ & $70.4 \%$ & & & \\
\hline \multicolumn{7}{|l|}{ Ulceration } \\
\hline Present & 61 & $76.5 \%$ & $60.3 \%$ & $<.0001(39.745)$ & $1.569(.499-4.933)$ & .441 \\
\hline Absent & 83 & $98.8 \%$ & $94.4 \%$ & & & \\
\hline \multicolumn{7}{|l|}{ Breslow's Thickness } \\
\hline$<1.55$ & 72 & $100 \%$ & $98.4 \%$ & $<.0001(42.747)$ & $10.855(1.101-107.057)$ & .041 \\
\hline$\geq 1.55$ & 72 & $78.7 \%$ & $61.7 \%$ & & & \\
\hline \multicolumn{7}{|l|}{ Mitotic rate } \\
\hline$<3$ & 60 & $98.3 \%$ & $94.2 \%$ & $<.0001(17.848)$ & $1.311(.373-4.606)$ & .673 \\
\hline$\geq 3$ & 84 & $82.9 \%$ & $70.1 \%$ & & & \\
\hline \multicolumn{7}{|l|}{ Clark's level } \\
\hline I and II & 47 & $100 \%$ & $100 \%$ & $.002(9.706)$ & $.667(.216-2.063)$ & .482 \\
\hline III, IV and V & 97 & $84.7 \%$ & $71.4 \%$ & & & \\
\hline \multicolumn{7}{|l|}{ Distant metastasis } \\
\hline Present & 34 & $67.5 \%$ & $41.2 \%$ & $<.0001(62.087)$ & $2.277(.512-10.135)$ & .280 \\
\hline Absent & 110 & $96.3 \%$ & $92.8 \%$ & & & \\
\hline \multicolumn{7}{|l|}{ AJCC-stage } \\
\hline In situ & 15 & $100 \%$ & $100 \%$ & $<.0001(71.219)$ & $1.438(.650-3.181)$ & .369 \\
\hline I & 51 & $100 \%$ & $100 \%$ & & & \\
\hline II & 42 & $90.4 \%$ & $80.1 \%$ & & & \\
\hline III & 23 & $69.3 \%$ & $55.4 \%$ & & & \\
\hline IV & 13 & $69.2 \%$ & $27.7 \%$ & & & \\
\hline \multicolumn{7}{|l|}{ p-Akt1 } \\
\hline High expression & 69 & $80.8 \%$ & $64.2 \%$ & $<.0001(24.206)$ & $2.766(.952-8.038)$ & .062 \\
\hline Low expression & 75 & $98.6 \%$ & $94.1 \%$ & & & \\
\hline
\end{tabular}

CSS - Cancer-specific survival, HR - Hazard Ratio, AJCC - American Joint Committee on Cancer. Bold values indicate statistical significance $(P<.05)$.

$(P=.008)$, AJCC-stage $(P<.0001)$, and recurrence $(P<.0001)$, as shown in Table 4. For oral melanomas, p-Aktl expression showed association with vascular invasion $(P=.001)$, mitotic rate $(P<.0001)$, and epithelioid cellular morphology $(P<.0001)$, as displayed in Table 5. In addition, in the SNM cohort (Table 6), vascular invasion $(P=.008)$, mitotic rate $(P=.023)$, and fusiform cellular morphology $(P=.009)$ were significantly associated with the positive p-Akt1-nuclear expression.

\section{p-Akt1 expression is higher in metastatic cutaneous melanomas and mucosal melanomas than in non-metastatic cutaneous melanomas}

p-Akt1 expression was tested in a large cohort of cutaneous, oral, and sinonasal melanomas, and it was expressed in tumour cells and occasionally in inflammatory cells surrounding the tumour. We also compared the scores of p-Akt1-positive nuclei into four groups: (a) primary (cutaneous melanoma) without metastatic history; and (b) primary (cutaneous melanoma) with metastatic history, (c) oral melanomas, and (d) sinonasal melanomas.

The p-Akt1 expression was predominantly detected in the nucleus, and non-metastatic cutaneous melanomas have a mean of $5.6 \%$ of the nuclei positive (ranging from $0 \%$ to $50.15 \%$ ). Primary metastatic cutaneous melanomas have a mean of $15.7 \%$ (ranging from $1.7 \%$ to $41.3 \%$ ). Cutaneous melanomas with low and high p-Akt1-nuclear expression are illustrated in Figure 1. The representative photomicrographs for p-Akt1 expression in oral and sinonasal melanomas are illustrated in Figures 2 and 3, respectively. Oral melanomas have scores of p-Akt1positivity (mean $=19.45 \%$, ranging from $2.6 \%$ to $44.4 \%$ ) 
similar to the cutaneous melanomas with metastatic history. The sinonasal melanomas demonstrated a higher number of nuclei positive for p-Akt1 (mean $=56.15 \%$, ranging from $15.1 \%$ to $82.6 \%$ ), statistically different from the other subtypes of melanomas analysed in this cohort (Figure 4). The nuclear p-Akt1-expression was closely related with invasive cells in all tumours, as illustrated in Figure 4.

\section{DISCUSSION}

The poor prognosis of patients with mucosal melanomas and their ineffective treatment options evidence that these tumours have a distinct biological signature, which is different from the other subtypes of melanomas [5, 10, 19]. Although some studies have extensively addressed the clinicopathological profile of the mucosal melanomas and their immunoprofile, these tumours have lacked predictive markers for tailored treatment [20-24]. Currently, the insufficient knowledge regarding molecular pathways that are selectively activated in different melanomas subtypes ensures comparative studies in mucosal and cutaneous melanomas. Herein, the authors proposed this comparative study to assess the p-Akt1 prognostic value in a series of cutaneous, oral, and sinonasal melanomas.

We used the AJCC system [25] for cutaneous melanomas staging. The AJCC-stage of cutaneous
A

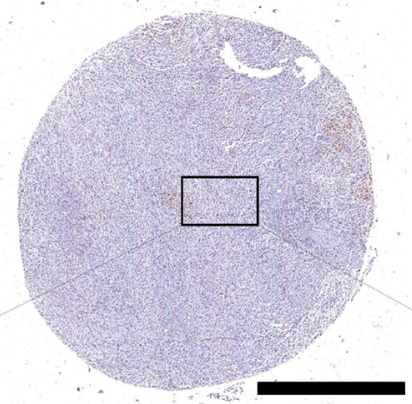

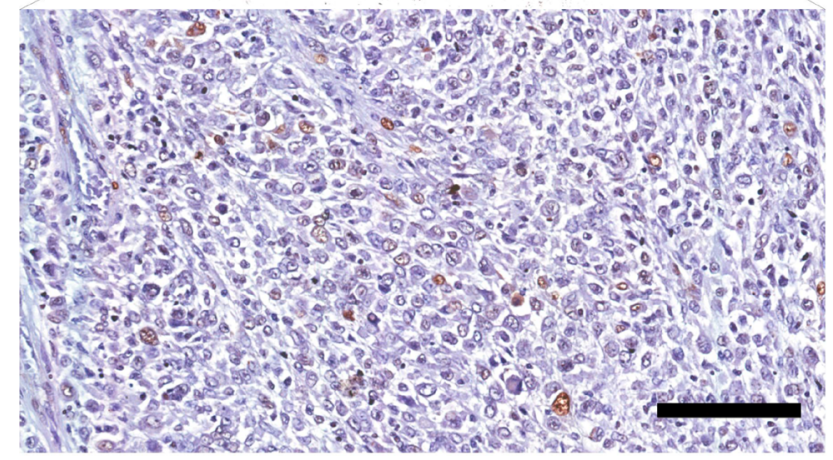

C

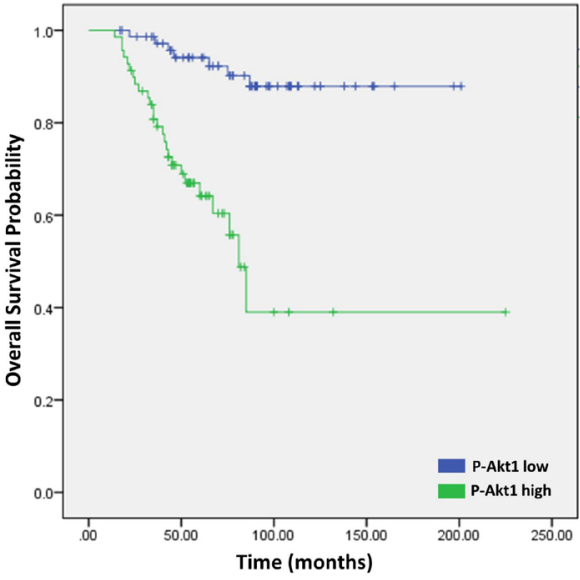

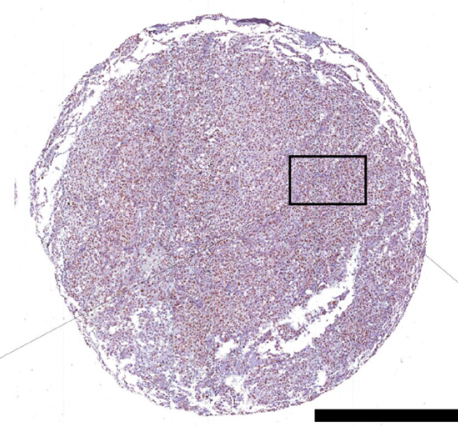

B

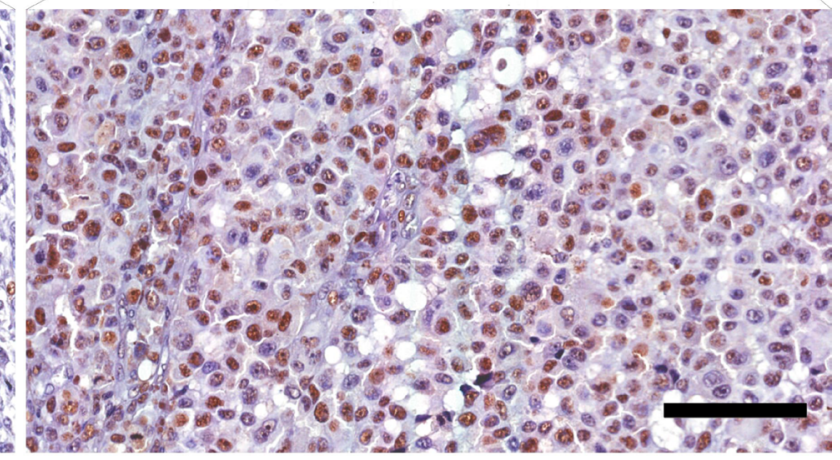

D

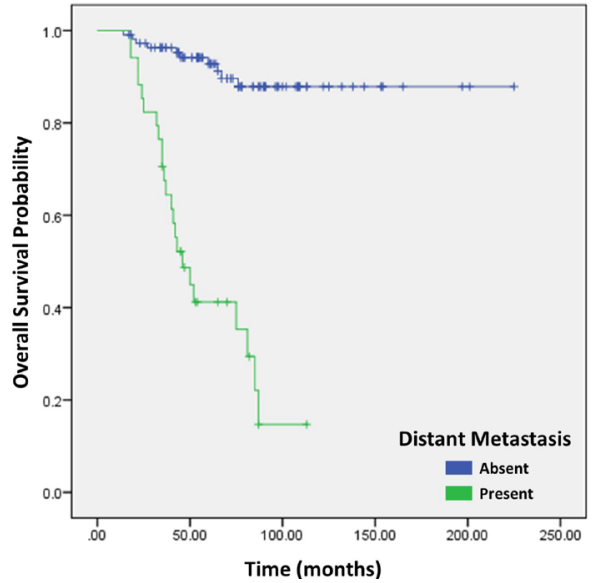

Figure 1: p-Akt1 expression in cutaneous melanomas. (A) Representative example of non-metastatic cutaneous melanoma in a tissue microarray, which was focally positive for p-Akt1. (B) Representative example of metastatic cutaneous melanoma in a tissue microarray, which was strongly positive for p-Akt1. (C) The association of p-Akt1nuclear expression and cancer-specific survival in cutaneous melanomas (logrank $=24.206, P<.0001)$. (D) The association of metastasis and cancer-specific survival in cutaneous melanomas (log-rank $=62.087, P<.0001)$. The scale bars represent $1 \mathrm{~mm}$ (top) and $100 \mu \mathrm{m}$ (bottom). 
melanoma's patients significantly affects the outcome, indicating that it is a reproducible method for suggesting the prognosis and therapeutic options. In this study, we also used the AJCC 7 th edition staging system for the mucosal melanomas. This system is more useful in prognosis prediction than the Ballantyne's staging system, which is mostly applied [19]. However, we used a dichotomized model (III/IV AJCC-stages), and the AJCCstaging had no impact on survival rates for oral melanoma patients, in the multivariate model. The relatively small number of cases, one limitation of our study, may explicate this finding. However, as mucosal melanomas of the head and neck are very rare tumours, the authors have provided novel information regarding sixty-five patients with oral and sinonasal melanomas.
Melanomas with predominant epithelioid morphology have been considered tumours of poor prognosis, as these neoplasms have greater DNA ploidy abnormalities when compared with other cellular morphologies in cutaneous melanomas [26]. Interestingly, in the current study, the epithelioid cellular morphology was found to be associated with a poor prognosis in oral melanomas, and it is in accordance with the findings from previous studies [27]. We also demonstrated a statistically significant association of the epithelioid cellular morphology with p-Akt1 overexpression, indicating a probable correlation between these two features. On the other hand, in sinonasal melanomas, only the undifferentiated cell morphology have been reported to confer poorer prognosis [28]. However, in this study,

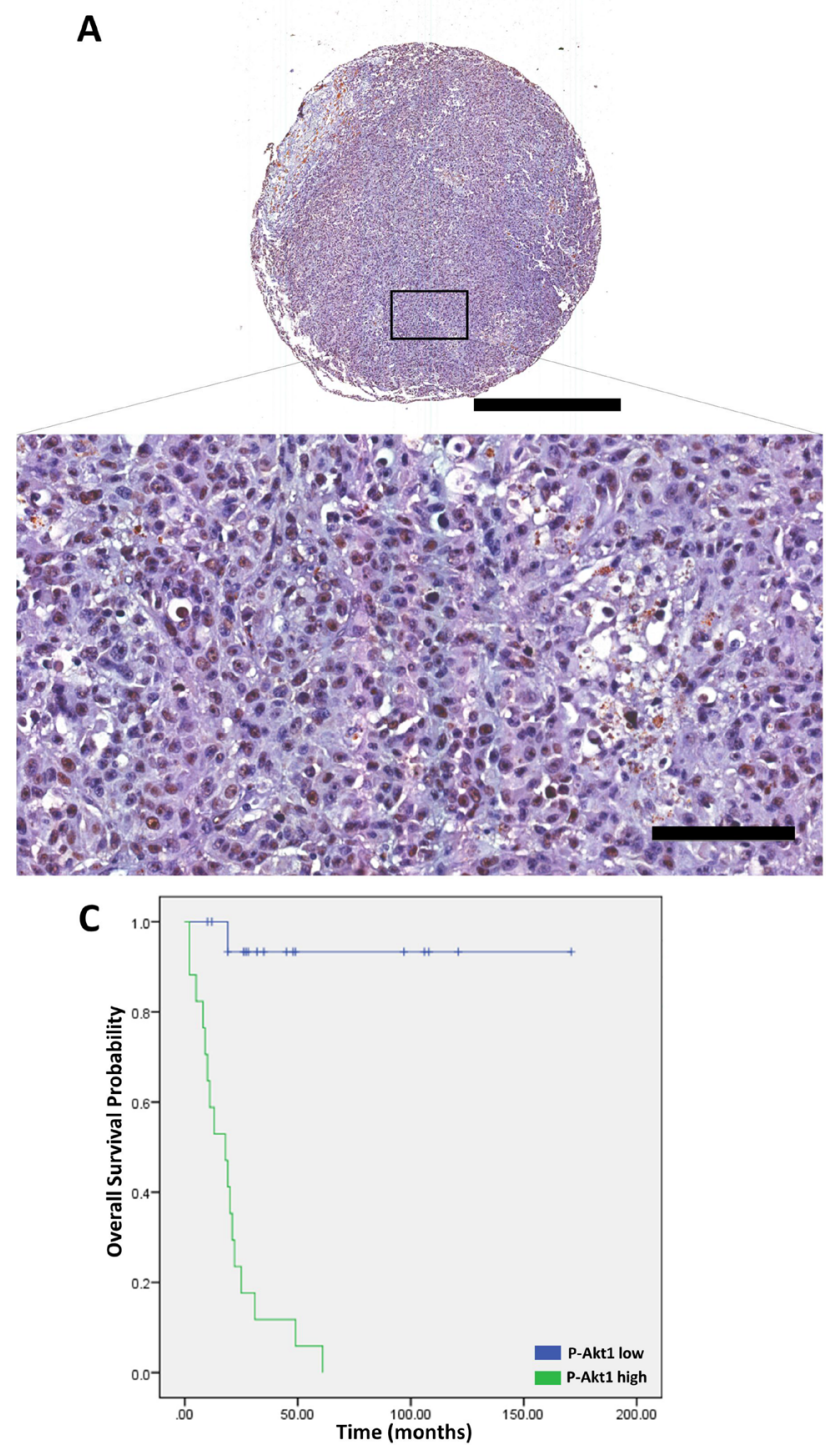

B
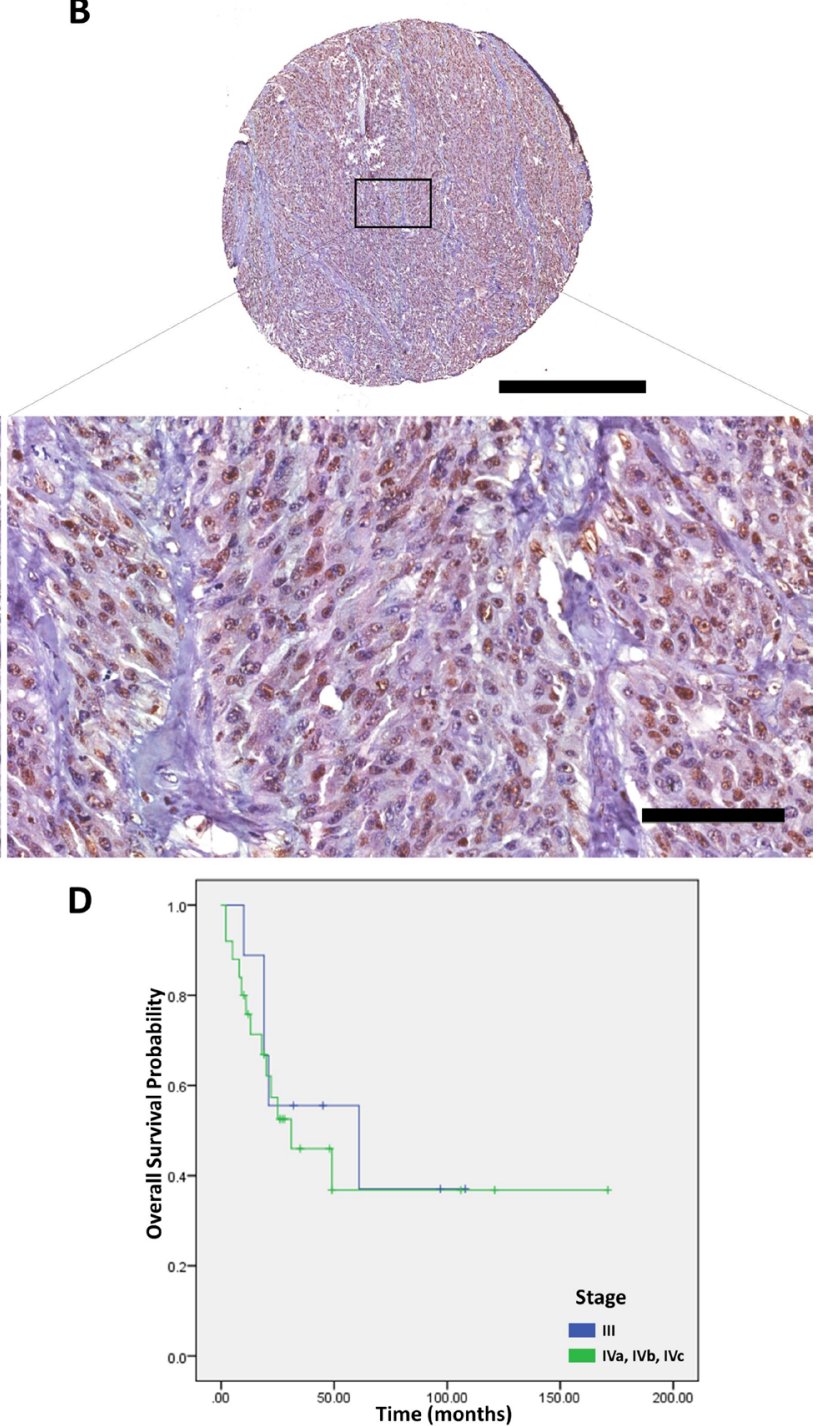

Figure 2: p-Akt1 expression in oral melanomas. (A) Representative example of oral melanoma in a tissue microarray, which was focally positive for p-Akt1. (B) Representative example of oral melanoma in a tissue microarray, which was strongly positive for p-Akt1. (C) The association of p-Akt1-nuclear expression and cancer-specific survival in oral melanomas $(\log$-rank $=28.086, P<.0001)$. (D) The association of AJCC-stage and cancer-specific survival in oral melanomas (log-rank =.168, $P=.682$ ). The scale bars represent $1 \mathrm{~mm}$ (top) and $100 \mu \mathrm{m}$ (bottom). 
Table 2: The relationship between clinicopathological characteristics of patients with oral melanomas, p-Akt1 expression and cancer-specific survival

\begin{tabular}{|c|c|c|c|c|c|c|}
\hline \multirow{2}{*}{ Factors } & \multirow{2}{*}{$\begin{array}{c}\text { Sample } \\
(\%)\end{array}$} & \multicolumn{2}{|c|}{ CSS (\%) } & \multirow{2}{*}{$\begin{array}{c}\text { Univariate } \\
P \text { (log-rank) }\end{array}$} & \multicolumn{2}{|c|}{ Multivariate } \\
\hline & & 3-year & 5-year & & HR $(95 \%$ CI) & $P$-value \\
\hline \multicolumn{7}{|l|}{ Age } \\
\hline$<47$ & $18(53.9)$ & $53.8 \%$ & $38.5 \%$ & $.926(.009)$ & $1.407(.237-8.361)$ & .707 \\
\hline$\geq 47$ & $16(46.1)$ & $41.5 \%$ & $41.5 \%$ & & & \\
\hline \multicolumn{7}{|l|}{ Gender } \\
\hline Female & $16(46.1)$ & $38.4 \%$ & $38.4 \%$ & $.374(.791)$ & $.718(.196-2.628)$ & .617 \\
\hline Male & $18(53.9)$ & $58.2 \%$ & $38.8 \%$ & & & \\
\hline \multicolumn{7}{|l|}{ Treatment } \\
\hline Only surgery & $22(64.7)$ & $55.4 \%$ & $55.4 \%$ & $.070(3.273)$ & $.689(.129-3.674)$ & .663 \\
\hline Surgery + chemo/radiotherapy & $11(32.4)$ & $38.1 \%$ & $12.7 \%$ & & & \\
\hline \multicolumn{7}{|l|}{ Anatomical site } \\
\hline Palate & $15(44.1)$ & $34.2 \%$ & $34.2 \%$ & $.113(4.355)$ & - & - \\
\hline Others & $19(55.9)$ & $68.8 \%$ & $55 \%$ & & & \\
\hline \multicolumn{7}{|l|}{ Mitotic rate } \\
\hline$<1$ & $14(41.2)$ & $85.1 \%$ & $85.1 \%$ & $.001(10.116)$ & $1.372(.154-12.212)$ & .777 \\
\hline$\geq 1$ & $20(58.8)$ & $26.9 \%$ & $13.5 \%$ & & & \\
\hline \multicolumn{7}{|l|}{ Vascular invasion } \\
\hline Absent & $21(61.8)$ & $80.4 \%$ & $58.6 \%$ & $<.0001(18.408)$ & $1.485(.191-11.579)$ & .706 \\
\hline Present & $13(38.2)$ & $0 \%$ & $0 \%$ & & & \\
\hline \multicolumn{7}{|l|}{ Neural invasion } \\
\hline Absent & $26(76.5)$ & $42.9 \%$ & $42.9 \%$ & $.011(6.467)$ & $4.622(.640-33.373)$ & .129 \\
\hline Present & $8(23.5)$ & $15.6 \%$ & $15.6 \%$ & & & \\
\hline \multicolumn{7}{|l|}{ Cellular morphology } \\
\hline Epithelioid & $22(64.7)$ & $30.3 \%$ & $20.2 \%$ & $.001(12.052)$ & $.927(.085-10.121)$ & .951 \\
\hline Non-epithelioid & $12(35.3)$ & $90 \%$ & $90 \%$ & & & \\
\hline \multicolumn{7}{|l|}{ AJCC-stage } \\
\hline III & $9(26.5)$ & $55.6 \%$ & $37 \%$ & $.682(.168)$ & $.885(.211-3.706)$ & .867 \\
\hline IVa, b and c & $25(73.5)$ & $46 \%$ & $36.8 \%$ & & & \\
\hline \multicolumn{7}{|l|}{$\mathrm{p}-\mathrm{Akt} 1$} \\
\hline High expression & $17(50)$ & $11.8 \%$ & $5.9 \%$ & $<.0001(28.086)$ & $11.397(1.102-117.855)$ & .041 \\
\hline Low expression & $17(50)$ & $93.3 \%$ & $93.3 \%$ & & & \\
\hline
\end{tabular}

CSS - Cancer-specific survival, HR - Hazard Ratio, AJCC - American Joint Committee on Cancer. Bold values indicate statistical significance $(P<.05)$

the spindle cell morphology was associated with worse prognosis for sinonasal melanoma patients.

The protein kinase $\mathrm{B}$ is serine/threonine-specific protein kinase involved in several biological activities in a wide range of cells, such as glucose metabolism and apoptosis [29]. To date, three isoforms of this protein have been well-described, AKT1, AKT2, and AKT3 [30]. AKT1 is widely documented for its activity in cellular metabolism of several human cancers [29] and when phosphorylated, p-Akt1 is described as playing an important role in the redox modulation of cell cycle progression [31]. On the other hand, Akt2 seems to play a critical role in cell proliferation through increased glycogen synthesis [32] and Akt3 expression is reported in normal tissues, including the brain, heart, kidney, and fat [33].

Previous studies have demonstrated that p-Akt1nuclear expression is closely associated with worse prognosis in breast [12], gastric [13], and oesophageal squamous carcinoma [14]. In opposition, it is associated 
Table 3: The relationship between clinicopathological characteristics of patients with sinonasal melanomas, p-Akt1 expression and cancer-specific survival

\begin{tabular}{|c|c|c|c|c|c|c|}
\hline \multirow[b]{2}{*}{ Factors } & \multirow{2}{*}{$\begin{array}{c}\text { Sample } \\
(\%)\end{array}$} & \multicolumn{2}{|c|}{ CSS (\%) } & \multirow{2}{*}{$\begin{array}{c}\text { Univariate } \\
P(\text { log-rank) }\end{array}$} & \multicolumn{2}{|l|}{ Multivariate } \\
\hline & & 3-year & 5-year & & HR (95\% CI) & $P$-value \\
\hline \multicolumn{7}{|l|}{ Age } \\
\hline$<58$ & $16(51.6)$ & $60.6 \%$ & $30.3 \%$ & $.701(.147)$ & $1.935(.479-7.820)$ & .354 \\
\hline$\geq 58$ & $15(48.4)$ & $51.3 \%$ & $38.5 \%$ & & & \\
\hline \multicolumn{7}{|l|}{ Gender } \\
\hline Female & $15(48.4)$ & $67 \%$ & $41.9 \%$ & $.319(.994)$ & - & - \\
\hline Male & $16(51.6)$ & $49.2 \%$ & $25.3 \%$ & & & \\
\hline \multicolumn{7}{|l|}{ Treatment } \\
\hline Only surgery & $13(41.9)$ & $63.5 \%$ & $25.4 \%$ & $.604(.268)$ & $.473(.132-1.694)$ & .250 \\
\hline Surgery + chemo/radiotherapy & $17(54.8)$ & $52.7 \%$ & $36.1 \%$ & & & \\
\hline \multicolumn{7}{|l|}{ Anatomical site } \\
\hline Nasal cavity & $13(41.9)$ & $56.6 \%$ & $45.3 \%$ & $.239(2.860)$ & - & - \\
\hline Others & $18(58.1)$ & $50 \%$ & $0 \%$ & & & \\
\hline \multicolumn{7}{|l|}{ Mitotic rate } \\
\hline$<1$ & $20(64.5)$ & $60.2 \%$ & $50.2 \%$ & $.401(.707)$ & $.361(.103-1.260)$ & .110 \\
\hline$\geq 1$ & $11(35.5)$ & $54.5 \%$ & $10.9 \%$ & & & \\
\hline \multicolumn{7}{|l|}{ Vascular invasion } \\
\hline Absent & $22(70.9)$ & $63.9 \%$ & $45.7 \%$ & $.042(4.151)$ & $.280(.072-1.080)$ & .065 \\
\hline Present & $9(28.1)$ & $44.4 \%$ & $11.1 \%$ & & & \\
\hline \multicolumn{7}{|l|}{ Neural invasion } \\
\hline Absent & $27(87.1)$ & $63.1 \%$ & $38.5 \%$ & $.072(3.230)$ & $3.223(.616-16.857)$ & .166 \\
\hline Present & $4(12.9)$ & $25 \%$ & $0 \%$ & & & \\
\hline \multicolumn{7}{|l|}{ Cellular morphology } \\
\hline Epithelioid & $9(29.1)$ & $100 \%$ & $62.5 \%$ & $.001(17.600)$ & $.582(.325-1.040)$ & .068 \\
\hline Fusiform & $13(41.9)$ & $15.4 \%$ & $7.7 \%$ & & & \\
\hline \multicolumn{7}{|l|}{ AJCC-stage } \\
\hline III & $9(28.1)$ & $85.7 \%$ & $64.3 \%$ & $.060(3.544)$ & $7.351(1.392-38.821)$ & .019 \\
\hline IVa, b and c & $22(70.9)$ & $45 \%$ & $20.2 \%$ & & & \\
\hline \multicolumn{7}{|l|}{ p-Akt1 } \\
\hline High expression & $20(64.5)$ & $42.2 \%$ & $12.1 \%$ & $.001(11.079)$ & $65.726(6.491-665.549)$ & $<.0001$ \\
\hline Low expression & $11(35.5)$ & $88.9 \%$ & $88.9 \%$ & & & \\
\hline
\end{tabular}

CSS - Cancer-specific survival, HR - Hazard Ratio, AJCC - American Joint Committee on Cancer. Bold values indicate statistical significance $(P<.05)$

with a favourable outcome in patients with pancreatic cancer [34]. The tumorigenic activity of p-Akt1 has also been investigated in several tumours [35-37] and in the context of tumour cells, Akt1 upregulates cell proliferation, invasion, and migration [38, 39]. Contrastively, its deletion prevents lung tumorigenesis in mice models [40]. One previous study shows the putative role of $\mathrm{p}$-Akt1 in metastatic cutaneous melanomas [41]. In this study, the nuclear p-Akt1 expression was associated with the presence of distant metastasis in patients with cutaneous melanomas. In fact, several studies have addressed the role of p-Akt1 in cancer progression and metastasis
[42], including its important part in the development of melanoma metastases in a mice model [18]. In addition, many studies have demonstrated the role of Akt1 in metastases development in several malignancies, such as colorectal [43] and lung [44] cancers. Although a correlation between $\mathrm{p}$-Akt1 expression and the metastatic status in cutaneous melanomas have been found for these tumours, the p-Akt1 showed prognostic values only in the univariate model, but it was lost in the multivariate model. In addition, p-Akt1 expression was correlated with important clinicopathologic features in the cutaneous melanomas, such as Breslow's thickness, Clark's level, 
mitotic rate, and AJCC-stage, indicating that p-Akt1 is correlated with melanoma tumorigenesis and affects the clinical outcome of these patients, emerging as a possible target for personalized therapies.

For oral and sinonasal melanomas, univariate and multivariate analysis identified p-Akt1 as an independent prognostic factor. Our results also showed that p-Akt1 expression was significantly higher in sinonasal melanomas than in oral and cutaneous melanomas. Taken together, these data support the hypothesis that sinonasal melanomas have distinct molecular signature and biological behaviour from its cutaneous counterpart. Importantly, we have demonstrated by immunohistochemistry that p-Akt1 is overexpressed in the nuclei of tumour cells and is closely correlated with poor outcome in a subset of mucosal melanomas, whereas the cutaneous melanomas demonstrated lower p-Akt1 expression compared with the oral and sinonasal melanomas. In fact, several studies have addressed the differences concerning etiologic factors and molecular pathways involved in the pathogenesis of cutaneous vs mucosal melanomas [3-5, 45]. For example, c-KIT aberrations were reported in tumours that have no correlation with chronic sun exposure (mainly mucosal melanomas). In opposition, the cutaneous counterpart frequently harbours mutations in the BRAF gene,
A

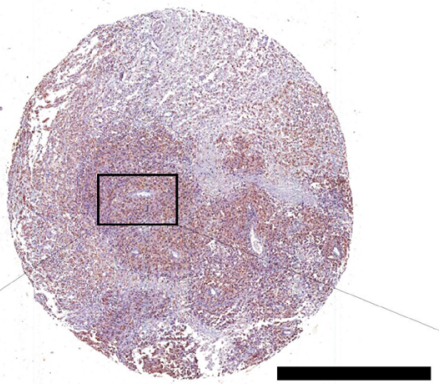

B

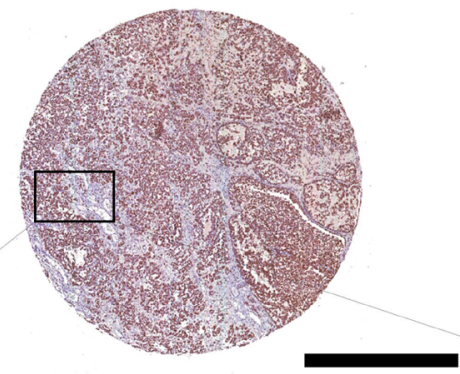

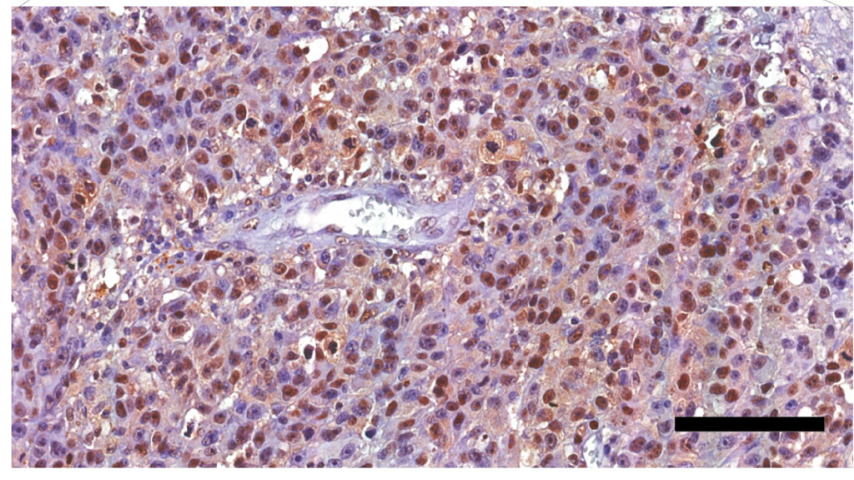

C

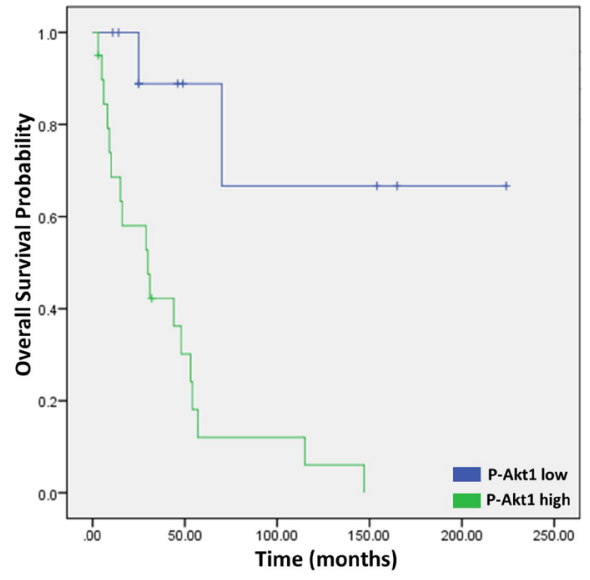

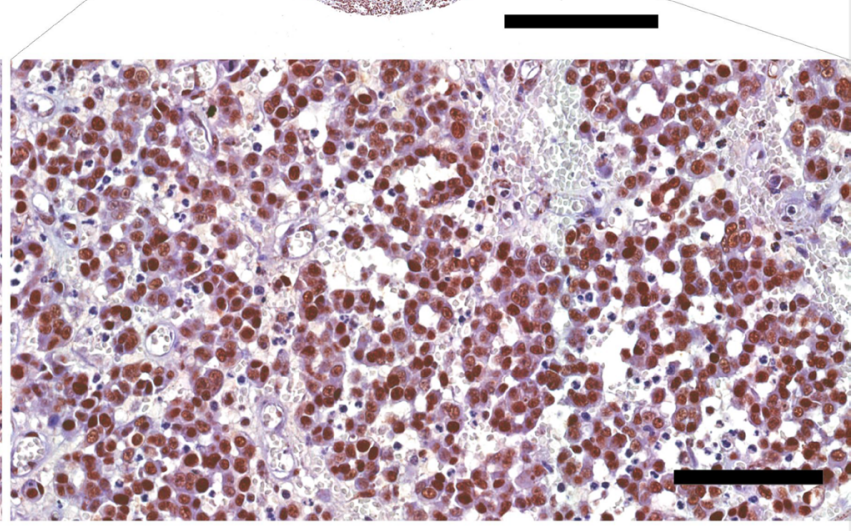

D

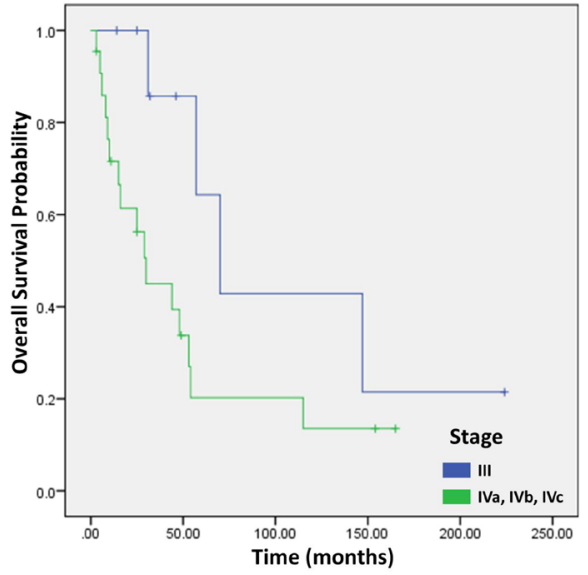

Figure 3: p-Akt1 expression in sinonasal melanomas. (A) Representative example of sinonasal melanoma in a tissue microarray, which was focally positive for p-Akt1. (B) Representative example of sinonasal melanoma in a tissue microarray, which was strongly positive for p-Akt1. (C) The association of p-Akt1-nuclear expression and cancer-specific survival in sinonasal melanomas (log-rank $=11.079$, $P=.001)$. (D) The association of AJCC-stage and cancer-specific survival in sinonasal melanomas $(\operatorname{logrank}=3.544, P=.060)$. The scale bars represent $1 \mathrm{~mm}$ (top) and $100 \mu \mathrm{m}$ (bottom). 
Table 4: The relationship between p-Akt1 nuclear expression and clinicopathological characteristics of 144 patients with cutaneous melanomas

\begin{tabular}{|c|c|c|c|}
\hline Clinicopathological characteristics & p-Akt1 low & p-Akt1 high & $P$-value \\
\hline Age $(<56 / \geq 56)$ & $44 / 31$ & $34 / 35$ & .259 \\
\hline Gender (Female/Male) & $39 / 36$ & $32 / 37$ & .500 \\
\hline $\begin{array}{l}\text { Site (Trunk/Head and neck/Upper limbs/Lower } \\
\text { Limbs) }\end{array}$ & $33 / 11 / 9 / 22$ & $31 / 11 / 9 / 18$ & .975 \\
\hline Ulceration (Absent/Present) & $63 / 12$ & $20 / 49$ & $<.0001$ \\
\hline Growth phase (Radial/Vertical) & $40 / 35$ & $15 / 54$ & $<.0001$ \\
\hline Breslow's Thickness $(<1.55 / \geq 1.55)$ & $59 / 16$ & $13 / 56$ & $<.0001$ \\
\hline Mitotic rate $(<3 / \geq 3)$ & $40 / 35$ & $20 / 49$ & .003 \\
\hline Clark's Level (I and II/III, IV and V) & $40 / 35$ & $7 / 62$ & $<.0001$ \\
\hline Metastasis (Absent/Present) & $64 / 11$ & $46 / 23$ & .008 \\
\hline AJCC-stage (in situ/I/II/III/IV) & $15 / 39 / 10 / 8 / 3$ & $0 / 12 / 32 / 15 / 10$ & $<.0001$ \\
\hline Recurrence (Absent/Present) & $61 / 14$ & $26 / 43$ & $<.0001$ \\
\hline
\end{tabular}

Table 5: The relationship between p-Akt1 nuclear expression and clinicopathological characteristics of 34 patients with oral melanomas

\begin{tabular}{|c|c|c|c|}
\hline Clinicopathological characteristics & p-Akt1 low & p-Akt1 high & $P$-value \\
\hline Age $(<47 / \geq 47)$ & $8 / 9$ & $10 / 7$ & .492 \\
\hline Gender (Female/Male) & $8 / 9$ & $8 / 9$ & 1.000 \\
\hline Site (Palate/alveolus/others) & $6 / 2 / 9$ & $9 / 3 / 5$ & .379 \\
\hline $\begin{array}{l}\text { Treatment (only surgery/surgery plus chemo- } \\
\text { radiotherapy) }\end{array}$ & $13 / 4$ & $9 / 7$ & .151 \\
\hline Vascular invasion (Absent/Present) & $15 / 2$ & $6 / 11$ & .001 \\
\hline Neural invasion (Absent/Present) & $14 / 3$ & $12 / 5$ & .419 \\
\hline Mitotic rate $(<1 / \geq 1)$ & $12 / 5$ & $2 / 15$ & $<.0001$ \\
\hline Necrosis (Absent/Present) & $14 / 3$ & $10 / 7$ & .132 \\
\hline Cellular morphology (Non-epithelioid/Epithelioid) & $12 / 5$ & $0 / 17$ & $<.0001$ \\
\hline Recurrence (No/Yes) & $14 / 3$ & $13 / 4$ & 671 \\
\hline
\end{tabular}

Table 6: The relationship between p-Akt1 nuclear expression and clinicopathological characteristics of 31 patients with sinonasal melanomas

\begin{tabular}{|c|c|c|c|}
\hline Clinicopathological characteristics & p-Akt1 low & p-Akt1 high & $P$-value \\
\hline Age $(<58 / \geq 58)$ & $5 / 6$ & $11 / 9$ & .611 \\
\hline Gender (Female/Male) & $7 / 4$ & $8 / 12$ & .208 \\
\hline Site (Nasal Cavity/Maxillary sinus/Rhinopharynx) & $6 / 5 / 0$ & $7 / 7 / 6$ & .126 \\
\hline Treatment (only surgery/surgery plus chemo-radiotherapy) & $5 / 6$ & $8 / 11$ & .741 \\
\hline Vascular invasion (Absent/Present) & $11 / 0$ & $11 / 9$ & .008 \\
\hline Neural invasion (Absent/Present) & $11 / 0$ & $16 / 4$ & .112 \\
\hline Mitotic rate $(<1 / \geq 1)$ & $10 / 1$ & $10 / 10$ & .023 \\
\hline Necrosis (Absent/Present) & $8 / 3$ & $10 / 10$ & .220 \\
\hline Cellular morphology (Epithelioid/Fusiform/Plasmacytoid-Undifferentiated) & $6 / 2 / 3$ & $3 / 11 / 6$ & .009 \\
\hline Recurrence (No/Yes) & $7 / 4$ & $12 / 8$ & .842 \\
\hline
\end{tabular}

given the fact that chronic sun exposure is important for its pathogenesis [9, 46]. It has been previously demonstrated that c-KIT is a key molecule for p-Akt1 activation through PI3K phosphorylation [46]. Therefore, particularly in mucosal melanomas, a correlation between p-Akt1 overexpression and c-KIT mutation may help to understand how these pathways are important for melanoma pathogenesis and patient outcomes. 
In the cohort of sinonasal melanomas analysed in this study, p-Akt1 overexpression showed a correlation with higher number of mitosis, presence of vascular invasion, and with spindle and undifferentiated cellular morphology. These findings provide new insights about the probable role of p-Akt1 in the aggressive genotype and phenotype of the sinonasal melanomas. In these particular tumours, necrosis was associated with overall survival in one previous report [47]. However, in this study's cohort, necrosis has not demonstrated prognostic predicting value, corroborating with other previous studies [48, 49]. No correlation between p-Aktl and necrosis was observed in this study.

Overall, the treatment of choice for both mucosal and cutaneous melanoma is the wide surgical resection [50-52]. Although it has been demonstrated that
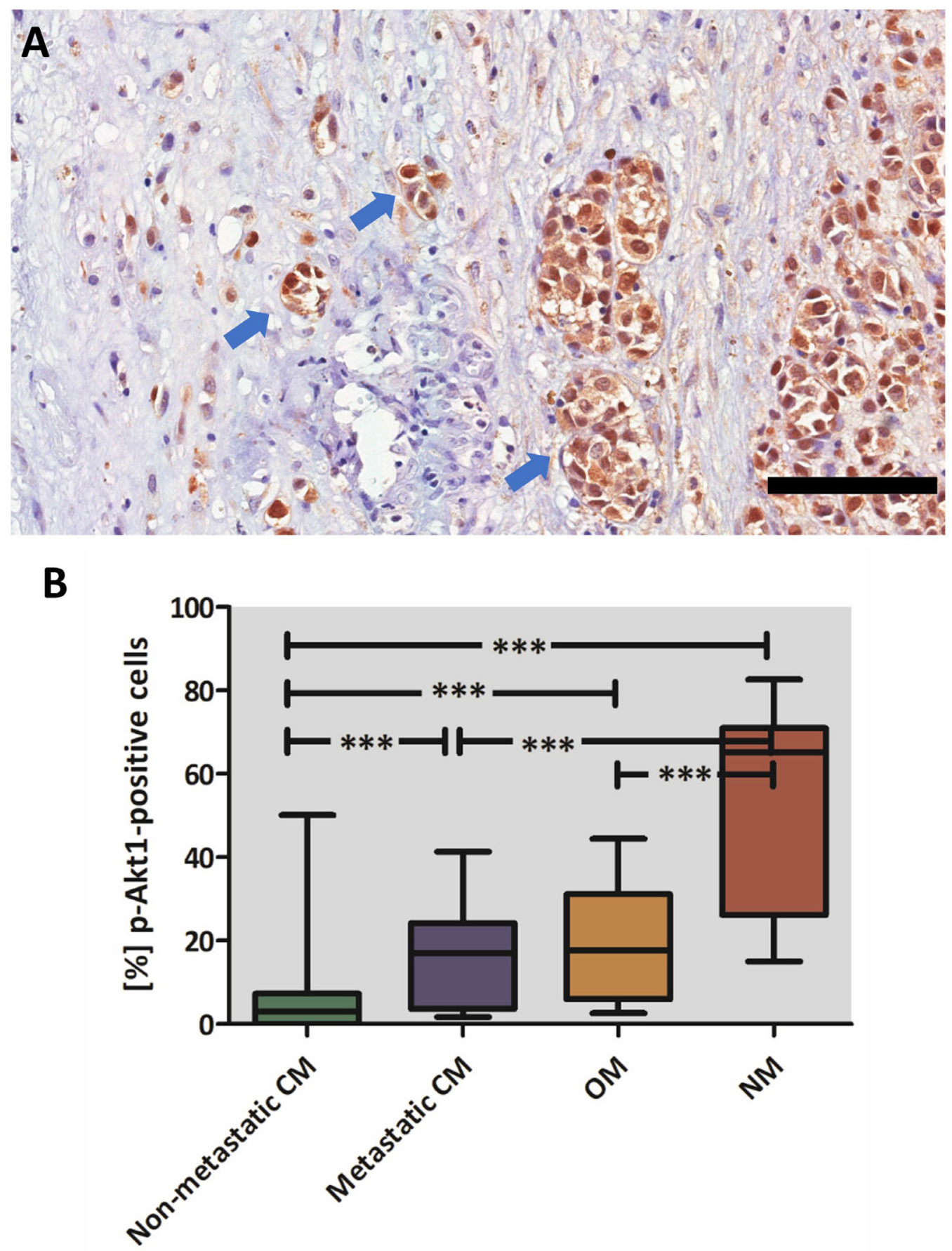

Figure 4: p-Akt1 expression in invasive cells and in different subgroups of melanomas. (A) Invasive cells strongly express p-Akt1 in the nucleus of a case of sinonasal melanoma. (B) Graphical representation of the median, minimum, and maximum scores of p-Akt1-nuclear positivity in the different subgroups of melanomas $\left({ }^{* * *}\right.$ indicates statistically significant difference between the groups, ANOVA test, $P$ value $<.00001)$. The scale bar represents $100 \mu \mathrm{m}$. 
melanomas are not radiosensitive, some tumours have been treated with adjuvant radiotherapy, and the use of these combined therapies are not standardized [10]. Regarding the mucosal melanomas, approximately $30 \%$ of the patients from the sample with oral melanomas and $50 \%$ of the patients with sinonasal melanomas received chemotherapy or radiotherapy as adjuvant treatment. Nevertheless, no differences in the cancer-specific survival were observed in both groups. The use of adjuvant therapies with surgical resection still needs to be investigated as a option to treat patients with mucosal melanomas [53].

In conclusion, the results of the current study demonstrated that p-Akt1 overexpression is an independent prognostic marker in mucosal melanomas and is significantly up-regulated in sinonasal melanomas. As both mucosal and metastatic cutaneous melanomas showed high frequency of p-Akt1 expression, our findings suggest that mucosal melanomas have a biological behaviour that is similar to the one identified in aggressive cutaneous melanomas.

\section{MATERIALS AND METHODS}

\section{Ethical issues}

The study protocol was approved by the National Commission for Ethics in Research (CONEP-Brazil, CAAE: 72077517.1.0000.5418) and all procedures were in accordance with the Declaration of Helsinki.

\section{Patient samples and data collection}

Cutaneous, sinonasal, and oral samples from the surgical samples of patients with melanoma who were referred to four Brazilian and Guatemalan cancer centers since 1997 were collected and further analysed. Melanoma diagnoses were confirmed by three experienced pathologists based on the microscopic examination of haematoxylineosin-stained slides, and on the S-100 protein, MART-1/ Melan A and gp-100 (HMB-45) expressions.

In total, 209 samples, including cutaneous $(n=144)$, oral $(n=34)$ and sinonasal $(n=31)$ melanomas. The first patient was included in May 1997 and the last patient in February 2016. Surviving patient follow-up was censored on September 10, 2017. Clinical data were collected from the patient's medical records which included age, sex, tumour location, metastases (presence/absence and site), clinical-stage, treatment options, and follow-up data. Tumour stage was determined according to the seventh edition of the staging manual of the American Joint Committee on Cancer [25].

\section{Tissue microarray construction}

For construction of the 7 tissue microarray blocks, a previously reported method was followed [41, 54]. Duplicate cores of $2 \mathrm{~mm}^{2}$ were collected from the original blocks of cutaneous, oral, and sinonasal melanoma patients.

\section{Immunohistochemistry (IHC) and digital scoring}

IHC manual technique was performed using 3-mm thick formalin-fixed paraffin-embedded melanomas sections mounted on silane-coated glass slides. An anti-Phospho-Akt1 (clone D7F10, 1:100 dilution; Cell Signalling, Danvers, Massachusetts, USA) was used. The antigen detection was achieved using the ADVANCE $^{\mathrm{TM}} / \mathrm{HRP}$ (code K406889-2; Dako, Carpinteria, CA, USA), revealed with the 3,3'-diaminobenzidinetetrahydrochloride chromogen and counterstained with Carazzi's haematoxylin.

All slides were scanned into high-resolution images with Aperio Scanscope CS Slide Scanner (Aperio Technologies Inc., Vista, California, USA). In order to calculate the scores of positivity expression of p-Akt1, digital analyses were performed, as previously described $[41,55]$. Nuclear p-Akt1 expression was scored based on the percentage [\%] of positive nuclei, assessed digitally with the Nuclear Algorithm (Aperio Technologies Inc.).

\section{Statistical analyses}

For the statistical analyses, all collected data were recorded in a password-protected computer database. All statistical analyses were carried out using the SPSS software, version 18.0 (SPSS Inc., Chicago, IL, USA). In the univariate model, the cancer-specific survival (CSS) (defined as the time between the start date of the treatment and the date of death due the disease) and disease-free survival (DFS) (defined as the time between treatment and recurrence) were estimated comparing the Kaplan-Meier survival curves using the log-rank test. The multivariate Cox regression was performed for prognostic significance determination of the p-Akt1 expression Index. For both univariate and multivariate models, the association between the variables age, sex, primary tumour site and p-Akt1 expression and CSS and DFS were evaluated. $p$-value $\leq .05$ was considered statistically significant.

\section{Abbreviations}

CM: cutaneous melanomas; OM: oral melanomas; SNM: sinonasal melanomas; HR: Hazard Ratio; AJCC: American Joint Committee on Cancer; p-Akt1: Phosphorylated Akt1, or protein B kinase 1; IHC: immunohistochemistry; CSS: Cancer-specific survival; DFS: disease-free survival.

\section{Author contributions}

Conception and design: CDS, JJ, OPA. Provision of study materials and/or patients: RC, FVMBC, MBC, 
RRDR, LSA, AMMA, MGFC, OPA. Collection and assembly of data: CDS, TMLM, MGFC, OPA, JJ. Data analysis and interpretation: CDS, TMLM, FVMBC, AMMA, JJ, Manuscript writing: CDS, TMLM. Final approval of manuscript: All authors approved the definitive version of this manuscript.

\section{ACKNOWLEDGMENTS}

The authors thank Dr. Gabriel Silva (MD) and Dr. Carlos Galvão (MD) for the support in the clinical and follow-up data.

\section{CONFLICTS OF INTEREST}

The authors have not conflicts of interest to disclose.

\section{FUNDING}

This work was supported by São Paulo Research Foundation (FAPESP), grants \#2015/25905-1, \#2017/16102-8 and \#2017/18134-4. None of the funding sources had any part in the study design, data collection/ analysis, data interpretation, or manuscript writing.

\section{REFERENCES}

1. Foletto MC, Haas SE. Cutaneous melanoma: new advances in treatment. An Bras Dermatol. 2014; 89:301-10.

2. Karimkhani C, Green AC, Nijsten T, Weinstock MA, Dellavalle RP, Naghavi M, Fitzmaurice C. The global burden of melanoma: results from the Global Burden of Disease Study 2015. Br J Dermatol. 2017; 177:134-40.

3. Korabiowska M, Brinck U, Hoenig JF, Bartkowski SB, Mirecka J, Schauer A. An application of MIB antibody to the retrospective study of melanomas of oral mucosa and facial skin. J Cancer Res Clin Oncol. 1994; 120:365-8.

4. Bishop KD, Olszewski AJ. Epidemiology and survival outcomes of ocular and mucosal melanomas: A populationbased analysis. Int J Cancer. 2014; 134:2961-71.

5. Kuk D, Shoushtari AN, Barker CA, Panageas KS, Munhoz RR, Momtaz P, Ariyan CE, Brady MS, Coit DG, Bogatch K, Callahan MK, Wolchok JD, Carvajal RD, et al. Prognosis of Mucosal, Uveal, Acral, Nonacral Cutaneous, and Unknown Primary Melanoma From the Time of First Metastasis. Oncologist. 2016; 21:848-54.

6. Alaeddini M, Etemad-Moghadam S. Immunohistochemical profile of oral mucosal and head and neck cutaneous melanoma. J Oral Pathol Med. 2015; 44:234-8.

7. Moreno MA, Roberts DB, Kupferman ME, Demonte F, El-Naggar AK, Williams M, Rosenthal DS, Hanna EY. Mucosal melanoma of the nose and paranasal sinuses, a contemporary experience from the M. D. Anderson cancer center. Cancer. 2010; 116:2215-23.
8. Patel SG, Prasad ML, Escrig M, Singh B, Shaha AR, Kraus DH, Boyle JO, Huvos AG, Busam K, Shah JP. Primary mucosal malignant melanoma of the head and neck. Head Neck. 2002; 24:247-57.

9. de Mendonça UB, Cernea CR, Matos LL, Toscano de Mendonça UB, Monteiro de Araujo Lima RR. Analysis of KIT gene mutations in patients with melanoma of the head and neck mucosa: a retrospective clinical report. Oncotarget. 2018; 9:22886-94. https://doi.org/10.18632/ oncotarget.25094.

10. Luna-Ortiz K, Villavicencio-Valencia V, Martinez Said H. Comparative study of head and neck mucosal melanoma in 66 patients vs 226 patients with cutaneous melanoma: A survival analysis. Clin Otolaryngol. 2018; 43:691-696.

11. Cicenas J. The potential role of Akt phosphorylation in human cancers. Int J Biol Markers. 2008; 23:1-9.

12. Liu J, Wei XL, Huang WH, Chen CF, Bai JW, Zhang GJ. Cytoplasmic Skp2 Expression Is Associated with p-Akt1 and Predicts Poor Prognosis in Human Breast Carcinomas. PLoS One. 2012; 7: e52675.

13. Cao F, Zhang C, Han W, Gao XJ, Ma J, Hu YW, Gu X, Ding HZ, Zhu LX, Liu Q. p-Akt as a potential poor prognostic factor for gastric cancer: a systematic review and metaanalysis. Oncotarget. 2017; 8:59878-88. https://doi. org/10.18632/oncotarget.17001.

14. Zhu Z, Yu W, Fu X, Sun M, Wei Q, Li D, Chen H, Xiang J, Li H, Zhang Y, Zhao W, Zhao K. Phosphorylated AKT1 is associated with poor prognosis in esophageal squamous cell carcinoma. J Exp Clin Cancer Res. 2015; 34: 95.

15. Vivanco I, Chen ZC, Tanos B, Oldrini B, Hsieh WY, Yannuzzi N, Campos C, Mellinghoff IK. A kinaseindependent function of AKT promotes cancer cell sur vival. eLife. 2014; 3:3.

16. Möser CV, Meissner M, Laarmann K, Olbrich K, KingHimmelreich TS, Wolters MC, Geisslinger G, Niederberger E. The protein kinase IKKepsilon contributes to tumour growth and tumour pain in a melanoma model. Biochem Pharmacol. 2016;103:64-73.

17. Montenegro RC, de Vasconcellos MC, Barbosa GS, Burbano RM, Souza LG, Lemos TL, Costa-Lotufo LV, de Moraes MO. A novel o-naphtoquinone inhibits N-cadherin expression and blocks melanoma cell invasion via AKT signaling. Toxicol In Vitro. 2013; 27:2076-83.

18. Cho JH, Robinson JP, Arave RA, Burnett WJ, Kircher DA, Chen G, Davies MA, Grossmann AH, VanBrocklin MW, McMahon M, Holmen SL. AKT1 Activation Promotes Development of Melanoma Metastases. Cell Rep. 2015;13:898-905.

19. Luna-Ortiz K, Aguilar-Romero M, VillavicencioValencia V, Zepeda-Castilla E, Vidrio-Morgado $\mathrm{H}$, Peteuil N, Mosqueda-Taylor A. Comparative study between two different staging systems (AJCC TNM VS BALLANTYNE'S) for mucosal melanomas of the head \& neck. Med Oral Patol Oral Cir Bucal. 2016;21: e425-30. 
20. Prasad ML, Busam KJ, Patel SG, Hoshaw-Woodard S, Shah JP, Huvos AG. Clinicopathologic differences in malignant melanoma arising in oral squamous and sinonasal respiratory mucosa of the upper aerodigestive tract. Arch Pathol Lab Med. 2003;127:997-1002.

21. Lourenço SV, A MS, Sotto MN, Bologna SB, Giacomo TB, Buim ME, Coutinho-Camillo CM, Silva SD, Landman G, Soares FA, Simonsen Nico MM. Primary oral mucosal melanoma: A series of 35 new cases from south America. Am J Dermatopathol. 2009; 31:323-30.

22. Benevenuto de Andrade BA, Piña AR, León JE, Paes de Almeida O, Altemani A. Primary nasal mucosal melanoma in Brazil: clinicopathologic and immunohistochemical study of 12 patients. Ann Diagn Pathol. 2012;16:344-9.

23. de Andrade BAB, León JE, Carlos R, Delgado-Azañero W, Mosqueda-Taylor A, de Almeida OP. Immunohistochemical expression of p16, p21, p27 and cyclin D1 in oral nevi and melanoma. Head Neck Pathol. 2012; 6:297-304.

24. de-Andrade BAB, Toral-Rizo VH, León JE, Contreras E, Carlos R, Delgado-Azañero W, Mosqueda-Taylor A, de-Almeida OP. Primary oral melanoma: a histopathological and immunohistochemical study of 22 cases of Latin America. Med Oral Patol Oral Cir Bucal. 2012; 17: e383-8.

25. Edge SB, Compton CC. The american joint committee on cancer: The 7th edition of the AJCC cancer staging manual and the future of TNM. Ann Surg Oncol. 2010; 17:1471-4.

26. Chi HI, Uyeda Y, Umebayashi Y, Otsuka F. Epithelioid cell melanomas have greater DNA ploidy abnormalities than spindle cell melanomas: cytological evidence for a higher malignant potential of the former. Arch Dermatol Res. $1993 ; 285: 410-4$.

27. Song H, Wang L, Lyu J, Wu Y, Guo W, Ren G. Loss of nuclear BAP1 expression is associated with poor prognosis in oral mucosal melanoma. Oncotarget. 2017; 8:29080-90. https://doi.org/10.18632/oncotarget.16175.

28. Narasimhan K, Kucuk O, Lin HS, Heilbrun LK, Carron M, Venkatramanamoorthy R, Mathog R. Sinonasal mucosal melanoma: a 13-year experience at a single institution. Skull Base. 2009; 19:255-62.

29. Carpten JD, Faber AL, Horn C, Donoho GP, Briggs SL, Robbins CM, Hostetter G, Boguslawski S, Moses TY, Savage S, Uhlik M, Lin A, Du J, et al. A transforming mutation in the pleckstrin homology domain of AKT1 in cancer. Nature. 2007; 448:439-44.

30. Santi SA, Lee H. The Akt isoforms are present at distinct subcellular locations. Am J Physiol Cell Physiol. 2010; 298:C580-91.

31. Arciuch VGA, Galli S, Franco MC, Lam PY, Cadenas E, Carreras MC, Poderoso JJ. Akt1 intramitochondrial cycling is a crucial step in the redox modulation of cell cycle progression. PLoS One. 2009;4:e7523.

32. Garofalo RS, Orena SJ, Rafidi K, Torchia AJ, Stock JL, Hildebrandt AL, Coskran T, Black SC, Brees DJ, Wicks JR, McNeish JD, Coleman KG. Severe diabetes, age-dependent loss of adipose tissue, and mild growth deficiency in mice lacking Akt2/PKB $\beta$. J Clin Invest. 2003;112:197-208.

33. Easton RM, Cho H, Roovers K, Shineman DW, Mizrahi M, Forman MS, Lee VMY, Szabolcs M, de Jong R, Oltersdorf T, Ludwig T, Efstratiadis A, Birnbaum MJ. Role for Akt3/ Protein Kinase B in Attainment of Normal Brain Size. Mol Cell Biol. 2005;25:1869-78.

34. Liu J, Cheng Sun SH, Sun SJ, Huang C, Hu HH, Jin YB, Qiu ZJ. Phosph-Akt1 expression is associated with a favourable prognosis in pancreatic cancer. Ann Acad Med Singapore. 2010;39:548-7.

35. Shen G, Rong X, Zhao J, Yang X, Li H, Jiang H, Zhou Q, Ji T, Huang S, Zhang J, Jia H. MicroRNA-105 suppresses cell proliferation and inhibits PI3K/AKT signaling in human hepatocellular carcinoma. Carcinogenesis. 2014;35:2748-55.

36. Wu Y, Kim J, Elshimali Y, Sarkissyan M, Vadgama JV. Activation of Akt1 accelerates carcinogen-induced tumorigenesis in mammary gland of virgin and postlactating transgenic mice. BMC Cancer. 2014;14:266.

37. Franks SE, Briah R, Jones RA, Moorehead RA. Unique roles of Akt1 and Akt2 in IGF-IR mediated lung tumorigenesis. Oncotarget. 2016; 7:3297-316. https://doi. org/10.18632/oncotarget.6489.

38. Yang L, Xiao L, Ma X, Tang M, Weng X, Chen X, Sun L, Cao Y. Effect of DNAzymes targeting Akt1 on cell proliferation and apoptosis in nasopharyngeal carcinoma. Cancer Biol Ther. 2009;8:366-71.

39. Chen L, Kang QH, Chen Y, Zhang YH, Li Q, Xie SQ, Wang CJ. Distinct roles of Akt1 in regulating proliferation, migration and invasion in HepG2 and HCT 116 cells. Oncol Rep. 2014; 31:737-44.

40. Hollander MC, Maier CR, Hobbs EA, Ashmore AR, Linnoila RI, Dennis PA. Akt1 deletion prevents lung tumorigenesis by mutant K-ras. Oncogene. 2011; 30:1812-21.

41. Soares CD, Borges CF, Sena-Filho M, Almeida OP, Stelini RF, Cintra ML, Graner E, Zecchin KG, Jorge J. Prognostic significance of cyclooxygenase 2 and phosphorylated Akt1 overexpression in primary nonmetastatic and metastatic cutaneous melanomas. Melanoma Res. 2017; 27:448-56.

42. Ooms LM, Binge LC, Davies EM, Rahman P, Conway JRW, Gurung R, Ferguson DT, Papa A, Fedele CG, Vieusseux JL, Chai RC, Koentgen F, Price JT, et al. The Inositol Polyphosphate 5-Phosphatase PIPP Regulates AKT1-Dependent Breast Cancer Growth and Metastasis. Cancer Cell. 2015; 28:155-69.

43. Agarwal E, Brattain MG, Chowdhury S. Cell survival and metastasis regulation by Akt signaling in colorectal cancer. Cell Signal. 2013; 25:1711-9.

44. Yu S, Zhang C, Dong F, Zhang Y. miR-99a Suppresses the Metastasis of Human Non-Small Cell Lung Cancer Cells by Targeting AKT1 Signaling Pathway. J Cell Biochem. 2015; 116:268-76. 
45. Turri-Zanoni $\mathrm{M}$, Medicina $\mathrm{D}$, Lombardi $\mathrm{D}$, Ungari $\mathrm{M}$, Balzarini P, Rossini C, Pellegrini W, Battaglia P, Capella C, Castelnuovo P, Palmedo G, Facchetti F, Kutzner H, et al. Sinonasal mucosal melanoma: Molecular profile and therapeutic implications from a series of 32 cases. Head Neck. 2013; 35:1066-77.

46. Lourenço SV, Fernandes JD, Hsieh R, Coutinho-Camillo CM, Bologna S, Sangueza M, Nico MMS. Head and neck mucosal melanoma: A review. Am J Dermatopathol. 2014; 36:578-87.

47. Mochel MC, Duncan LM, Piris A, Kraft S. Primary mucosal melanoma of the sinonasal tract: a clinicopathologic and immunohistochemical study of thirty-two cases. Head Neck Pathol. 2015; 9:236-43.

48. Thompson LDR, Wieneke JA, Miettinen M. Sinonasal tract and nasopharyngeal melanomas: a clinicopathologic study of 115 cases with a proposed staging system. Am J Surg Pathol. 2003; 27:594-611.

49. Prasad ML, Patel SG, Huvos AG, Shah JP, Busam KJ. Primary mucosal melanoma of the head and neck. Cancer. 2004; 100:1657-64.

50. Mendenhall WM, Amdur RJ, Hinerman RW, Werning JW, Villaret DB, Mendenhall NP. Head and neck mucosal melanoma. Am J Clin Oncol. 2005; 28:626-30.
51. McLean N, Tighiouart M, Muller S. Primary mucosal melanoma of the head and neck. Comparison of clinical presentation and histopathologic features of oral and sinonasal melanoma. Oral Oncol. 2008; 44:1039-46.

52. Warszawik-Hendzel O, Słowińska M, Olszewska M, Rudnicka L. Melanoma of the oral cavity: pathogenesis, dermoscopy, clinical features, staging and management. J Dermatol Case Rep. 2014; 8:60-6.

53. Cheng YF, Lai CC, Ho CY, Shu CH, Lin CZ. Toward a Better Understanding of Sinonasal Mucosal Melanoma: Clinical Review of 23 Cases. J Chin Med Assoc. 2007; 70:24-9.

54. Montezuma MAP, Fonseca FP, Benites BM, Soares CD, do Amaral-Silva GK, de Almeida OP, Soares FA, Pagano RL, Fregnani ER. COX-2 as a determinant of lower disease-free survival for patients affected by ameloblastoma. Pathol Res Pract. 2018; 214:907-913.

55. Fonseca FP, Bingle L, Santos-Silva AR, Lopes MA, de Almeida OP, de Andrade BA, Mariano FV, Kowalski LP, Rangel AL, Martins MD, Meurer L, Speight PM, Vargas PA. Semaphorins and neuropilins expression in salivary gland tumors. J Oral Pathol Med. 2016; 45:119-26. 